\title{
Special issue on the estimation of gravity models of bilateral trade: Editors' introduction
}

\author{
Badi H. Baltagi ${ }^{1}$ • Peter H. Egger ${ }^{2}$ • \\ Michael Pfaffermayr ${ }^{3}$
}

We were fortunate to have been able to solicit papers for this special issue of Empirical Economics from the CESifo Workshop entitled "On the estimation of gravity models of bilateral trade" that took place on May 30-31, 2014, in Munich, Germany. The workshop was organized by the guest editors, and the local organization and sponsorship were generously provided by CESifo as well as ETH Zurich to which we are thankful.

This special issue in Empirical Economics contains important contributions for the gravity model of bilateral trade as well as econometric methodology applied to this model. These include simultaneous quantiles regression, a random coefficients model, generalized linear models (GLMs), and fixed effects panel data models.

All of the papers selected for this special issue have gone through the usual process of peer review for Empirical Economics, and we would like to thank all of the referees for their hard work.

Badi H. Baltagi

bbaltagi@maxwell.syr.edu

Peter H. Egger

egger@kof.ethz.ch

Michael Pfaffermayr

michael.pfaffermayr@uibk.ac.at

1 Department of Economics and Center for Policy Research, Syracuse University, Syracuse, NY 13244-1020, USA

2 ETH Zurich and CEPR, LEE G101, Leonhardstrasse 21, 8092 Zurich, Switzerland

3 Department of Economics, University of Innsbruck, Universitätsstr. 15, 6020 Innsbruck, Austria 


\section{Summary of contributions}

Theoretical models of international trade assume that the partial elasticity of trade flows with respect to observable trade costs is constant across the (conditional as well as unconditional) quantiles of bilateral trade flows. Baltagi and Egger provide evidence which casts doubt on this question based on simultaneous quantiles regression model, and data on bilateral exports and trade costs demonstrate that observable trade-cost measures in logs are not linearly related to overall log trade costs in 2008 . As is customary in the related empirical literature on gravity models of international trade, trade costs are specified as a log-additive function of geographical, cultural, and historical observables in a structural model of bilateral trade. In this model, trade costs differ not only statistically but also quantitatively across the quantiles of the conditional distribution of bilateral exports. As a consequence, comparative static effects of these trade costs vary as well, and this is the case-qualitatively and quantitatively-different from standard nonlinear structural models of trade.

Figueiredo, Lima, and Schaur use quantile regression models for panel data to examine the effects of the introduction of the Euro on trade. This framework is robust to heteroskedasticity bias and helps identifying the effect of interest across the entire distribution of bilateral trade flows. Using this estimator, the authors come to the conclusion that the introduction of the Euro had negligible effects throughout the distribution.

A strand of recent empirical work in international trade emphasizes the role of cultural factors-especially common languages-for bilateral trade. Fidrmuc and Fidrmuc add to this literature by analyzing the importance of speaking foreign languages for international trade. The authors use standard as well as quantile regressions to address this question in a sample of European Union member as well as candidate non-member countries. The authors' results suggest that a widespread knowledge of foreign languages stimulates international trade in a quantitatively important way, and knowledge of English appears to play a special role in that regard.

Some authors in international economics recently assumed that bilateral trade costs contain a stochastic component. In fact, related work assumes that the disturbance term in gravity model is a measure of the stochastic component of trade costs (e.g., see Eaton and Kortum 2002; Anderson and Wincoop 2004; Helpman et al. 2008). Egger and Pruša address the structure of this random component of trade costs and decompose it into parts that pertain to a measurement error of bilateral distances, of bilateral tariffs, and a random component which is unrelated to observable measures of trade costs. The authors do so by means of a random coefficients model and a cross-sectional sample of bilateral trade data for 96 countries in 2005. The data confirm that there is indeed a large random component about the partial trade elasticity which relates to the measurement of bilateral distance and bilateral tariffs. The partial elasticity of trade with respect to tariffs in different countries varies even relatively more than that with respect to distance. This is consistent with measurement error about bilateral tariffs which emerges for reasons such as the strategic or non-strategic misreporting of tariffs or due the potential inappropriateness of the (trade- or frequency-) weighting of disaggregated tariffs when analyzing aggregate bilateral trade flows. 
Foliano, Gasiorek, and Cirera analyze to which extent unilateral trade preferences granted by developed countries to developing economies through reductions in applied tariffs have been effective at increasing exports of developed economies. The paper focuses on an evaluation of the effects of the European Union's (EU) unilateral preferential regimes, estimating bilateral gravity models at the product level. The authors employ a unique dataset with variation at the Combined Nomenclature (CN) 10-digit product level which permits determining the actual tariff rate applied to each export flow to the EU and the preferential regime of entry. In particular, this dataset permits addressing the relative importance of utilization versus non-utilization of trade preferences. The authors find, as one would expect, that unilateral preferences have been effective in increasing exports to the EU-it should be noted that earlier evidence which was based on less detailed data had been mixed. The most effective preferential regimes are found to be the EU's free trade agreements and the GSP+. There is little evidence that preferences have had an additional positive impact on the extensive margin of trade (i.e., preferential tariff regimes are granted to countries where there is already some trade).

Spring and Grossmann examine to which extent bilateral trust across countries affects international trade and migration. Following Guiso et al. (2009), they employ average physical dissimilarities ("somatic distance") between the populations of two countries in a pair as a proxy variable for the difference in trust between economic agents in two countries. They employ seven alternative somatic distance indicators in addition to the one by Guiso et al. (2009). Since all of those are equally valid instruments, it should not matter which one is used in two-stage least squares estimations. However, the results turn out to be highly sensitive to the choice of the instrument. The authors find that only when using the instrument of Guiso et al. (2009) do the results support a statistically significant effect of bilateral trust on international trade. Bilateral trust never enters significantly at the second stage when using bilateral migration instead of bilateral trade as an outcome variable. Overall, their results cast doubt on the impact of bilateral trust on international trade or migration.

Many empirical gravity models of international trade are now based on GLMs. The Poisson pseudo-maximum likelihood estimator is the most prominent example and the most frequently used estimator of those. Gravity models of international trade imply a structure where the linear index employed in a GLM is in fact a nonlinear function of structural variables. From earlier work on the estimation of GLMs with trade models, we do not know how different GLM estimators perform in small- to medium-sized samples of country pairs, if trade flows are generated by general equilibrium models of trade as they are often assumed in modern empirical work. Egger and Staub add to this literature by studying the small-sample performance of GLM estimators in a data-generating process that is fully consistent with general equilibrium economic models of international trade. Economic theory suggests that importer- and exporterspecific effects are nonlinear implicit functions of the exogenous model variables and parameters and that they are correlated with bilateral trade costs through generalequilibrium (or balance-of-payments) restrictions. They compare the performance of various empirical models - such as iterative structural estimators, fixed effects estimators, and quasi-differences estimators - in such settings, using the GLM approach as a unifying framework. 
While most of the applied econometric work on the analysis of gravity models assumes that the disturbances are independently (if not identically) distributed across country pairs, some recent work promotes the consideration of cross-sectional dependence of the disturbances (e.g., see Anderson and Wincoop 2004; LeSage and Kelley Pace 2008; Kristian et al. 2012). Using a cross-sectional data structure, Egger and Pfaffermayr propose error component models with random versus fixed exporter and importer country effects as well as a remainder, pair-specific component. Moreover, they allow for spatial interdependence which is determined by geographical distance between countries and country pairs in some or even all of these components. They derive such models for balanced as well as unbalanced data structures. In an empirical application with cross-sectional bilateral trade data for 93 countries, they show that the stochastic terms are indeed interdependent in all possible dimensions when using a customary parametrization of the trade-cost function and spatial weights matrices which are informed by the geographical distance among countries.

Martínez-San Román, Bengoa, and Sanchez-Robles examine empirically the pattern of FDI flows within the European Union and the relevance of trade integration for that pattern, using investment flows over the period 1995-2009. They capture trade integration primarily by means of the home bias, rather than by using direct indicators of tariff and non-tariff barriers to trade. The measure of the home bias employed by the authors is estimated for the countries in the sample by a standard gravity model. In the sample at hand, the authors find a positive and robust correlation between trade integration and FDI activity. Moreover, the results suggest that FDI in the European Union is of a hybrid type rather than of a simple horizontal (market seeking; trade-cost jumping) or a simple vertical (low-cost seeking) type. The authors' findings are consistent with a knowledge-capital hybrid model, where considerations about the market size of the partners and their relative endowment of skilled labor are jointly relevant.

\section{References}

Anderson JE, van Wincoop E (2004) Trade costs. J Econ Lit 42(3):691-751

Behrens K, Ertur C, Koch W (2012) 'Dual' gravity: using spatial econometrics to control for multilateral resistance. J Appl Econom 27(5):773-794

Eaton J, Kortum SS (2002) Technology, geography, and trade. Econometrica 70(5):1741-1779

Guiso L, Sapienza P, Zingales L (2009) Cultural biases in economic exchange? Q J Econ 124(3):1095-1131

Helpman E, Melitz M, Rubinstein Y (2008) Estimating trade flows: trading partners and trading volumes. Q J Econ 123(2):441-487

LeSage JP, Kelley Pace R (2008) Spatial econometric modelling of origin-destination flows. J Reg Sci 48(5):941-967 